\title{
Personality Analysis Based on the Behavior Language Program (BLP) Assessment
}

\author{
Chenfeng Gao*
}

\author{
University of Technology Sydney, Sydney 2007, Australia \\ ${ }^{*}$ Corresponding author. Email: 13473121@student.uts.edu.au
}

\begin{abstract}
Personality assessment tools are widely used in companies, especially in China, which serves as a tool to find the appropriate employee during recruitment screen out the target consumer for new markets. On this basis, this paper and aims to investigate the personality based on Behavior Language Program (BLP) assessment for Chinese. Primarily, the theories of most of the personality assessment tools are introduced. According to previous literature, it is found that the personality analysis has not completed the Sinicization (e.g., 16PF and MBTI), where BLP is not one of them. Through the analysis of the BLP evaluation report and interviews with the participant, the statement is verified that the personality formation comes from family factors, self-regulation factors and social factors. Based on the personality type, the corresponding strengths and weaknesses of the personality are elaborated. These results offer a guideline for participants to understand their own personality and adjust behavior to quickly integrate into the team.
\end{abstract}

Keywords: personality assessment, personality formation, strengths and weaknesses with personality.

\section{INTRODUCTION}

Personality affects the motives of human daily behavior. Merenda states the Four Temperament theory, which believes that the human body is composed of four different liquids (sanguine, choleric, melancholic, and phlegmatic) [1]. The difference in human behavior is caused by these four liquids. For example, choleric makes people irritable and sanguine is good at communication. Currently, most companies in China use personality assessment systems to select suitable employees. Cai states that the application of personality assessment in China has just begun to be used, which lags behind the western country [2]. In addition, he also states that personality assessment tools can help companies assign suitable jobs according to their characteristics when selecting employees. DISC divides personality into four tendencies: Dominance (D), Inducement (I), Submission (S) and Compliance (C). Marston states that everyone has these four factors, and the difference in behavior between people is due to the different degrees of performance of these four factors [3]. The Nurturing Center for Chinese Leadership of Beijing Normal University has developed the 'Behavior Language Program (BLP)' that based on DISC. This article will select a report from the BLP database, and then contact the subject for an interview. Subsequently, the reasons for the formation of the personality of the report will be analyzed through the content of the interview. Finally, the way to communicate with others at work will be discussed.

\section{LITERATURE REVIEW}

Trait theory of personality has developed in the early 20th century. Initially, the research on personality traits mainly focused on Four Temperament theory. In this period, many scholars have defined personality traits, and different definitions caused different theories. Most scholars divide the traits of personality into two parts: introversion and extroversion. Regarding the introversion and extroversion of personality traits, Allport states that personality is divided into common traits and unique traits [4]. Common traits refer to the external behavior of individuals receiving external stimuli. Specific traits refer to a general psychological structure that allows individuals to produce different behavior styles through external stimuli [4]. Similarly, Cattell divides personality into surface traits and inner layers of personality structure. Cattell states that the external manifestations of individual behavior belong to the surface traits but not the essence of personality [5]. The essence of personality needs to be discovered through the surface traits and the inner layer of the personality structure. Generally, there 
are sixteen personality traits: Warmth, Reasoning, Emotional Stability, Dominance, Liveliness, RuleConsciousness, Social Boldness, Sensitivity, Vigilance, Abstractedness, Privateness, Apprehension, Openness to Change, Self-Reliance, Perfectionism, and Tension [5].

Big Five personality is a model developed based on Cattell's 16PF. Tupes and Christal state that surgency, agreeableness, dependability, emotional stability, and culture can cover all characteristics [6]. Costa and McCrae state that personality traits are composed of Openness to experience, Conscientiousness, Extraversion, Agreeableness and Neuroticism [7]. To be specific, (1) openness to experience is defined as being willing to try new things and being creative; (2) conscientiousness refers to an individual's self-discipline or self-control in order to achieve external expectations; (3) extraversion is defined as an individual Like to interact with the outside world and shovel passion; (4) agreeableness is a description of an individual's tendency to value getting along with others and is willing to compromise; (5) neuroticism is defined as an individual's ability to withstand pressure [7]. Eysenck points out that personality has two dimensions, which are extraversion and neuroticism [8]. However, Eysenck and Eysenck states that psychoticism is also a dimension of personality traits. In Eysenck's research, neuroticism and psychoticism belong to the introversion of personality traits [9]. Neuroticism refers to the differences between individuals in terms of emotional stability. For example, people who are emotionally stable are easier to restore calm. Psychoticism refers to the negative personality traits in an individual, e.g., coldness. Jung directly divides personality into introversion and extroversion [9]. Jung demonstrates that extraversion refers to the individual's focus on the object, the external world of sensory perception, focusing on objective things. With regard to introversion, it refers to the individual reflecting on his internal world, focusing on the subjective [10]. In addition, Jung states that extraversion and introversion combined with sensing, intuition, thinking and feeling will form eight personality types [10]. This theory put forward by Jung provided strong support for the followup MBTI.

Currently, these personality assessment tools used by most companies in personnel selection are developed from the above-mentioned theories. MBTI, 16PF and Big Five personality are widely used in personnel selection, but these assessment tools have some shortcomings for Chinese. Firstly, they will face the problem of localization of assessment tools. Fehriinger states that each culture has its own worldview and sense of value [11]. The cultural atmospheres of the Chinese and the people in Western countries are different, which leads to differences in the interpretation of certain words. Thus, simply translates of $16 \mathrm{PF}$ or MBTI will lead to inappropriate results due to cultural differences. In addition, the $\mathrm{Gu}$ and $\mathrm{Hu}$ argue that MBTI scale only has the first level $\mathrm{G}$ and $\mathrm{M}$ scales that have been localized in China [12]. Compared with 16PF and MBTI, the Big Five personality model proved to be able to be used in different languages and different cultural environments [13]. Huang claims that if Chinese use the assessment tools used by people in Western countries, it can only measure the Chinese reaction to the content contained in the assessment tool, but not the content contained in the Chinese personality [14].

Secondly, the use of assessment tools in China requires the construction of Chinese people's own database. For example, MBTI did not build a database belonging to the Chinese in the process of localization in China. As a matter of fact, China has not established a database that belongs to the distribution of Chinese personality types for MBTI [12]. As a consequence, data analysis can only be compared between sample groups or with data from other countries [12]. If the Chinese have not constructed their own data model, it is impossible to know the differences between the types of Chinese people and those in Western countries. Similarly, without the Chinese own data model, every Chinese who does a personality assessment cannot know what position he is in the Chinese group.

Compared with the assessment tools mentioned above, the Behavior Language Program (BLP) not only builds the Chinese own data model, but also completes the chinesization on the basis of the DISC assessment tool. BLP is established by the Nurturing Center for Chinese Leadership of Beijing Normal University by analyzing the dimensions of the DISC assessment tool and setting up questions that can measure the content of Chinese personality. Therefore, the views in DISC are consistent with BLP. Marstonstates that people express their emotions according to four types of behaviors: Dominance (D), Inducement (I), Submission (S), and Compliance (C) [3]. For the dimensions of evaluation, BLP and DISC are the same as measuring the four dimensions proposed by Marston. Whereas, unlike the DISC assessment, the BLP results show the scores of D, I, S, and C in three different aspects: stressful situations, natural situations and the eyes of others. Table 1 shows the common descriptions about D, I, S, and C.

Table 1. Description of common features of D, I, S and $\mathrm{C}$

\begin{tabular}{|c|c|c|c|}
\hline \multicolumn{2}{|c|}{ D/Dominance } & \multicolumn{2}{|c|}{ I/Inducement } \\
\hline a. & $\begin{array}{l}\text { Strong sense } \\
\text { purpose }\end{array}$ & ofa. & $\begin{array}{l}\text { Not afraid of impromptu } \\
\text { speeches }\end{array}$ \\
\hline b. & Victorious & b. & Willing to express one's \\
\hline c. & High initiative & & emotions \\
\hline d. & Strong execution & c. & optimism \\
\hline e. & Have confidence & d. & High initiative \\
\hline f. & Not afraid & ofe. & Information Sharing \\
\hline
\end{tabular}




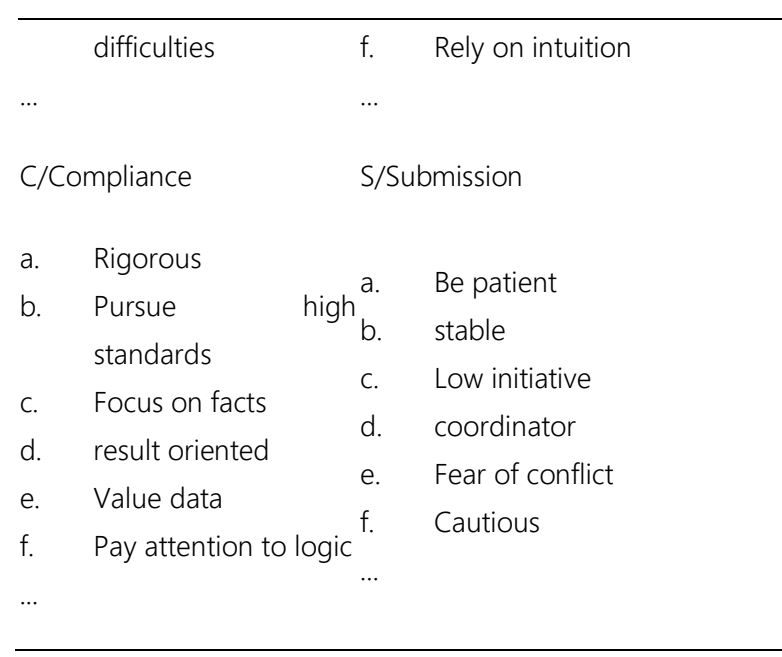

\section{DISCUSSION}

The shaping of personality is not a single process, which is affected by social and cultural factors, family environment factors, early childhood experience, school education factors and self-regulation factors. Freud expresses that the structure of personality is divided into id, ego and super-ego [15]. In detail, id refers to the instinct of the individual, which is the source of physical needs and desires; ego refers to the behavior of the individual to please id while considering reality constraints; super-ego is defined as the last stage of personality formation, which is mainly influenced by parents, education and guidance [15]. Similarly, consciousness, personal unconsciousness and collective unconsciousness constitute the three levels of personality. Specifically, consciousness refers to the process of an individual's socialization, in which an individual's interaction with others and society causes an individual to become unique [16]. However, the formation of personality is shaped by multiple experiences. As shown in Figure 1, the participant's D and I tendencies are 98 points and 10 points, respectively, in a natural situation. Therefore, in the analysis of the participant's personality tendencies, interviews will be carried out to investigate the impact of representative things one believes in the growth on the formation of the $\mathrm{D}$ and I tendencies.

\subsection{From family perspective}

\subsubsection{D tendency}

As shown in Figure 1, one' s D tendency score of 98 in the BLP evaluation results belongs to a group of people with extremely high D tendency. According to the BLP report, people with high $\mathrm{D}$ tendencies have a higher sense of competition. Besides, they dislike being dominated by others and focus on facts and results as well as act quickly, but lack persistence. Moreover, they dare to make decisions in cooperation with others, but lack of feedback. In addition, in the process of cooperation, they will ignore the ideas of others because they are too strong. People with high $\mathrm{D}$ tendencies are likely to have extremely high self-confidence and enjoy challenges. The high D tendency mainly comes from the parents' education. Deqing Racuo pointed out that family plays a vital role in the formation of personality, because the behavior between parents in the early childhood will be learned by the children [17]. For example, the way of communication between parents in the early childhood period is likely to have an impact on the interpersonal communication of the young child throughout his life. According to the characteristics pointed out in the above report, the $\mathrm{D}$ tendency is so high that it is affected by his mother. His mother is an extremely powerful person in the family and hates to seek help. When he was in a difficult family situation as a child, his mother kept telling him that he should bear it herself when encountering difficulties. If he actively seeks help, he must consider the interests or feelings of the people who helped him when he wants to do something in the future. In addition, his mother has high self-esteem. When he was in elementary school the family conditions were very poor and his father was a very ordinary worker. In a family gathering, several of his elders expressed contempt for his father. In order not to let others look down on his family, his mother supported his father to start a business though everyone thinks it is not profitable. During his growth, these events have been constantly occurred. His mother has always emphasized that as a person, one must have own ideas and dare to practice for the ideas instead of worrying about the difficulties that will be encountered. During the formation of the D tendency, his mother's aversion to owe others' favor, the maintenance of self-esteem and the decisiveness in decision-making all had a huge impact on him. He agrees with some of his mother's education and hopes to be a figure like his mother.

Based on above description, it can be easily found that the whole process of personality formation is affected by the family. His identification with his mother's education led him to hate being dominated by others and possess a high level of self-esteem. Similar to his mother, he would think that the outcome of things was good and would do it without considering the difficulties he would face in the process. Besides, these traits are all traits possessed by $\mathrm{D}$ tendencies in personality.

\subsubsection{I tendency}

As shown in Figure 1, the score for I propensity in this BLP report is only 10 points. The score of I tendency is far below average, i.e., it is difficult for the interview to possess the characteristics of I tendency. This means that when facing a problem, he will not focus too much on the person, but on the matter. People with higher I tendency will express their feelings or feelings more actively, while low I tendencies lead to their 
unwillingness to actively express their feelings and seldom give feedback to others. In addition, people with I tendencies are likely not to be afraid of impromptu speeches. During the interview, he indicated that he is reluctant to speak in public in most cases. In addition, his parents would often teach him how to control his emotions and not to express his emotions at will when he was young. In the learning phase, most Chinese teachers educate students to be humble instead of being open.

According to above analysis, it can be easily found that causing his I tendency score to be lower than the average is affected by the education of his parents. When he was young, his parents taught him not to express his emotions and to control his emotions. Besides, this education is the opposite of the traits in the I tendency. Individuals with I tendency traits prefer to express their emotions rather than silence.

\subsection{From social perspective}

\subsubsection{D tendency}

From the perspective of the social environment, the internship in that year of junior college may be one of the reasons for his extremely high $\mathrm{D}$ tendency. The human resources department asked him to do a PDP test during the year of internship in the junior college. The result of the PDP is that he has a strong tendency to dominance. However, when the PDP test is performed again at the undergraduate level, the tendency for dominance is higher than during the previous internship. In the year of internship in the junior college, the company's personnel manager placed him in a job he didn't like and promised to transfer him to the job he originally wanted in 3 months. However, the HR manager did not show any signs of transferring him when the three-month deadline was about to arrive. No matter how many times he consulted, he was blocked one by one. During this time, he kept reflecting on why others can dominate him. In the end, he attributed these to his academic qualifications, i.e., set himself a goal of completing an undergraduate degree. After reaching the goal, he pointed out that he felt happy and became more confident after completing the goal, so he kept setting goals and constantly achieving them. Up to now, he believes that he is able to handle the issues as long as the outcome of things can bring benefits.

From the above discussion, it can be easily found that $\mathrm{D}$ tends to be much higher than the average because he enjoys the joy of achieving the goal and is not afraid of the difficulties in the process of achieving the goal. The characteristic of $\mathrm{D}$ tendency is that the individual has a very clear goal, and will achieve the goal without fear of difficulties. Therefore, as long as he continues to achieve his goals, his D tendency will remain at a high level.

\subsubsection{I tendency}

From the perspective of social environment, one of the main reasons why his I tendency score is lower than the norm is also from that period of internship experience. In the PDP assessment conducted at the junior college and undergraduate levels, the tendency of extroversion also dropped significantly. According to the description of I inclination in the BLP assessment, people with I inclination will more easily tell others about their vision, be interpersonal-oriented and trust others easily. During the interview, he pointed out that he cares much about people's visions for him. During the undergraduate internship, as a member of the human resources department, he rarely explained his vision to the interviewees during the interview. He believes that if the stated vision is not achieved, it will be a deception. He further pointed out that this idea was mainly because he was cheated by HR to do work that he did not like, and he failed to honor the agreement between the two parties eventually.

One of the characteristics of I tendencies is that individuals will express their future visions like others. During the internship, because HR did not fulfill his promises, he was unwilling to express his future vision with others and he was unwilling to believe in others' promises. Thereby, it resulted in I tend to be lower than average.

\subsection{Strengths and weaknesses and future development}

As depicted in Figure 1, the BLP assessment report shows that his personality tends to be D-dominant, which changes to DC only under stress. People with D tendency as the leader have the following advantages. First, they are result-oriented and high concentration. They dare to express their opinions directly and only focus on problem solving in the process of work cooperation. Second, D tendency is the leader that are highly mobile, which like challenges and are not afraid of innovation. In addition, they dare to make decisions. Therefore, $\mathrm{D}$ tends to be the leading person who is suitable for opening up new markets for the company or leading organizational changes to adjust the organizational structure.

However, people with D tendencies also have some disadvantages. For example, in this BLP evaluation report, his D tendencies are above average while other options are below average. This situation has the following disadvantages. First, because of his low I tendency, he may be overly concerned about things and ignore others in cooperation. Second, his $\mathrm{C}$ tendency will increase under pressure, which means that under pressure, his behavior will pay more attention to facts and the pursuit of details will be more stringent. The management grid theory proposes that managers who focus too much on the business itself while ignore the 
employees themselves are authoritarian managers. This type of manager will make employees lose the innovation ability because they only need employees who can meet high standards. Therefore, the innovation ability of subordinates might not get the opportunity to play. Finally, people with $\mathrm{D}$ as the leader dare to make decisions. Therefore, whether in life or at work, this type of people often does not listen to the opinions of others when faced with choices. It will also cause some wrong behaviors in management decisions.

Different personality tendencies lead to different behaviors and concerns when thinking about problems, which will bring conflicts in work. On this occasion, his situation from the communication style will be first analyzed, and then the way to get along with people of different personalities in the future will be discussed. As illustrated in Figure 1, his tendency in the natural state is shown as D tendency. In terms of communication style, people with $\mathrm{D}$ tendencies are more inclined to brief and effective communication. In addition, since his $\mathrm{C}$ tendency is below average in the general state, it means that he is not sensitive to data and not logically in the general situation. Secondly, people with D tendencies want to talk about topics that capture the topic rather than irrelevant topics. Besides his I and $\mathrm{S}$ tendencies are also very low, indicating that he will not focus on people's reactions but on things during the communication process. As for work, he and people with D tendencies will be divided into the following three situations. (1) People with D tendencies act as leaders. In the process of getting along, one should pay attention to the effectiveness of communication. If the character of the superior is DC, he should improve his rigor in the work process; if the superior is DS, then he should be focus on the ideas of superiors; if it is DI, then he needs to learn to tolerate the description of some visions in the usual way of getting along. (2) People with D tendencies are regarded as peers. In addition to focusing on the effectiveness of communication, they also need to clarify their job responsibilities. Regardless of whether it is facing the level of DC, DS or DI, the same can be done as above. (3) People with D tendencies are subordinates, who don't like to be dominated. When you encounter this type of subordinate in future work, you should give them clear performance goals and enough trust. Moreover, get along with people with I tendency as the leading factor.

People with I tendency as the leading factor will focus on their own emotional expression and be willing to describe their vision for the future. In addition, people with I tendencies do not like to be bound by rules. When getting along with this kind of people, as superior leaders, whether it is I, IS, ID or IC, they will describe their vision for the future when they become managers. Therefore, he should learn to tolerate the description of the vision with such people. In addition, IS-leaning managers may avoid conflicts compared to other-leaning managers. Therefore, their silence often means rejection. As peers and subordinates, one should give them enough feedback as much as possible.

With regard to $\mathrm{S}$ tendencies people, they are very sensitive to emotional changes and prefer a stable environment and atmosphere. In the future, in order to avoid conflict, he should understand other people' s behavior whether such they are his superiors, peers or subordinates. Their silence during communication is likely to represent rejection. In addition, when facing this type of subordinates, I type people should give them a clear direction and plan.

Finally, people who are led by $\mathrm{C}$ tendencies are very rational and pay great attention to quality. For instance, the people who dominated by $\mathrm{D}$ tendencies all focus on things themselves rather than people. Therefore, whether it is the superiors, ratings or subordinates of $\mathrm{C}, \mathrm{CS}, \mathrm{CI}$ or $\mathrm{CD}$, they should improve their professionalism and rigor when dealing with them in the future.
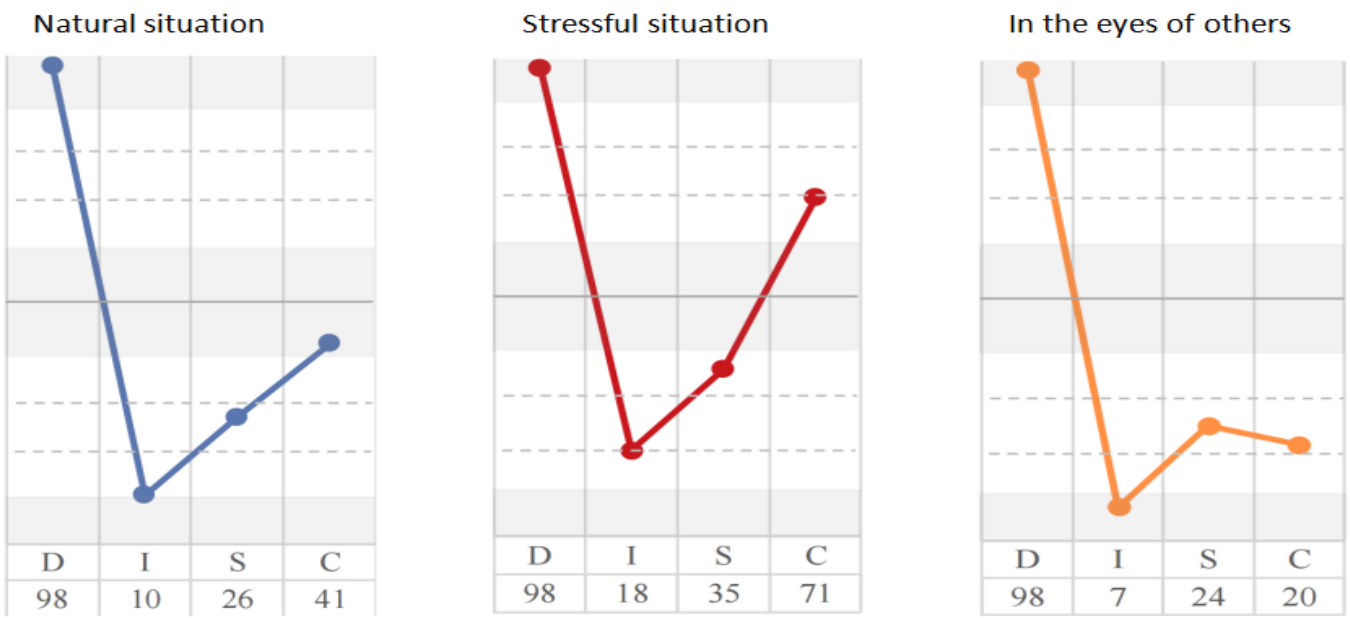

Figure 1. BLP result of participant in natural situations, stressful situations and in the eyes of others. 


\section{CONCLUSION}

In summary, the formation of personality is a complex process, which is affected by the individual's childhood experience, self-regulation factors, social factors, family environment and school education. Based on the results of the BLP report and interviews, it is known that the subject's D and I tendencies is originated by family, social factors, and self-regulation factors. From the perspective of the family environment, due to the mother's education and his own identity with the mother's behavior, the characteristics of the D tendency have been developed (e.g., not afraid of difficulties and dare to challenge). Since his parents taught him not to express his emotions freely when he was young, it led to the lack of growth in the traits of I tendency, e.g., his dislike of impromptu speech and his dislike of expressing himself. From the perspective of social factors, after reaching the goal, the participant thought that as long as the results are beneficial, he could do it instead of being afraid of the difficulties. Not afraid of difficulties is a common characteristic in D tendency. This type of behavior will cause the $\mathrm{D}$ tendency to grow continuously rather than suppressing. The tendency of I in the report to be lower than the average is mainly because HR did not realize the promise of both parties during the internship process, which led him to believe in the vision for no reason. The characteristics of I tendency indicate that people with higher than average I tendency are more willing to explain their vision to others. This internship experience provided growth for his D tendency and the difficulty inhibited the development of his I tendency. From the perspective of personal control factors, the identification of the mother's behavior and the identification of the parents' education lead him to be more willing to according to ancestor' $s$ behavior. Since his D tendency are too high and I and S tendency are too low, he will only pay too much attention to things and ignore people's feelings at work. Especially in stressful situations where $\mathrm{C}$ tendency to increase, he will become an authoritarian leader. In communication, he needs to develop rigor and learn to listen to the vision. In addition, he should learn to reduce conflict and understand the means of others' silence. These results shed light for participants to find the correct team positioning and adjust behaviors to quickly integrate into the new team.

\section{REFERENCES}

[1] Merenda, P. F. (1987). Toward a four-factor theory of temperament and/or personality. Journal of Personality Assessment, 51(3), 367-374.

[2] Shenggang, C. A. I. (2010). The Application of the Sixteen Personality Factor Questionnaire in Selection and Installation of Personnel [J]. Science and Technology Management Research, 24.
[3] Marston, W. M. (1928). Emotions of Normal People, London: Kegan Paul, Trench, Trubner Co. Ltd.

[4] Allport, G. W. (1961). Pattern and growth in personality.

[5] Cattell, R.B. (1965). The Scientific Analysis of Personality.

[6] Tupes, E. C., \& Christal, R. E. (1992). Recurrent personality factors based on trait ratings. Journal of personality, 60(2), 225-251.

[7] Costa, P. T., \& McCrae, R. R. (1985). The NEO personality inventory. Odessa, FL: Psychological assessment resources.

[8] Eysenck, H. J. (1950). Dimensions of personality (Vol. 5). Transaction Publishers.

[9] Eysenck, H. J., \& Eysenck, S. B. G. (1977). Psychoticism as a dimension of personality. Taylor $\&$ Francis Group.

[10] Jung, C. (1971). Collected works of CG Jung: No. 6: Psychological Types, Princeton.

[11] Fehriinger, H. M. (2004). Contributions and limitations of Cattell's sixteen personality factor model. Trabajo de investigacion en linea) citado el, 3.

[12] GU, X. Y., \& HU, S. (2012). MBTI: New development and application. Advances in Psychological Science, 20(10), 1700-1708.

[13] McCrae, R. R., \& Terracciano, A. (2005). Universal features of personality traits from the observer's perspective: data from 50 cultures. Journal of personality and social psychology, 88(3), 547.

[14] HUANG, X. T. (2004). Reflections on Chinanization of Personality Studies [J]. Journal of Southwest China Normal University (Philosophy \& Social Sciences Edition), 6.

[15] Freud, S. (1989). The ego and the id (1923). TACD Journal, 17(1), 5-22.

[16] Jung, C. G. (2014). The archetypes and the collective unconscious. Routledge.

[17] Deqing Lacuo. On the influence of "native family" on children's growth and character[J]. Modern Vocational Education,2020(46):184-185. 